YONG-GANG WANG, Ph.D.

E-mail: sdqdwyg@163.com

Chang'an University, School of Highway

Key Laboratory for Special Area Highway Engineering of

Ministry of Education

Middle Section of South 2 Ring Rd., Xi'an 710064, China

GANG WEI, B.Sc.

E-mail: Iuoi9001@163.com

CCCC First Highway Consultants Co., LTD

63 Kejierlu Rd., Xi'an 710075, China

XU ZHU, B.Sc.

E-mail: zhuxu2005@126.com

Chang'an University, School of Highway

Middle Section of South 2 Ring Rd., Xi'an 710064, China

YU-LONG PEI, Ph.D.

E-mail: yulongp@263.net

Harbin Institute of Technology

School of Transportation Science and Engineering

73 Huanghe Rd., Harbin 150090, China
Traffic in the Cities

Preliminary Communication

Accepted: Apr. 23, 2010

Approved: May 17, 2011

\title{
CAPACITY OF BICYCLE PLATOON FLOW AT TWO-PHASE SIGNALIZED INTERSECTION: A CASE ANALYSIS OF XI'AN CITY
}

\begin{abstract}
Although much is known about the operation of signalized intersections, little or no empirical research has been conducted regarding bicycle capacity at these locations and the correspondent contributory factors. The purpose of this study is to accurately quantify the capacity of bikeway at signalized intersection through a fluid dispersion approach, and ultimately the lane group capacity. Using this total dispersion of bicycle flow, a relationship is also described between bicycle volume per hour and per unit width, signal parameters (length of signal cycle and green time), bicycle flow (arrival rate, density, moving velocity) and geometric intersection distance. Through the videotaping of four intersections that have significant bicycle traffic around Xiaozhai in Xi'an, China, it is ascertained that bicycle capacity varies linearly (but limited by an asymptote domain) associated with the adjustment of these parameters. The analytical results indicate that the impact saturation flow of lane groups containing right-turning vehicles and pedestrian flow at signalized intersections on bicycles is being underestimated. If this is the case, then capacity is being overestimated through the HCM 2000 capacity model and JJ37-90 approach and intersections are not being adequately designed, due to the neglect of conflict nature of mixed traffic arrivals in competing for space.
\end{abstract}

\section{KEY WORDS}

bikeway capacity, signalized intersection, fluid dispersion, HCM 2000, signal parameter, fixed traffic

\section{INTRODUCTION}

Capacity is one of the key performance indicators to evaluate a signalized intersection level-of-service (LOS) for the passing elements (motor vehicle, bicycle flow, pedestrian traffic, etc.) [1]. Thus, the design of a signalized intersection is a trade-off between the safety of bicyclists and pedestrians and convenience for motor vehicles [2], particularly in the "kingdom of bicycles" - China. Like motor vehicles, more bicyclists need to cross an intersection safely within the given period. However, this need must be balanced against possible conflicts between the right turning motorized vehicles, pedestrians and bicyclists [3, 4]. In case of greater lengthening to accommodate bicyclists, then the delays for cross traffic may increase and the overall capacity of observed intersection may decrease, even endanger the road safety $[5,6]$. It is therefore necessary to estimate the capacity of bicycle flow accurately at signalized intersections under different traffic movements, intersection features and local constraints for intersection design and planning, but also for signal configuration and operation management.

Over the past decades, surveys have indicated that bicycles account for approximately 20-25 percent of trips by city residence, especially in central and western regions of China [7], and almost all cities have always focused on a healthy commuting mode through an integrated green system of on-street lanes and 
paths for bicycles. Of course, such efforts often cause significant reduction in LOS and capacity performance of intersection-related locations [8, 9]. A study by Allen et al. [10] highlights the quantitative impacts of total occupancy due to bicycles and pedestrians in reducing saturation flow and ultimately lane group capacity through the videotaping of intersections in Davis and Gainesville, and they also argue that the impact of sig nificant bicycle traffic on decreasing the capacity of signalized intersection may be overestimated according to the prevailing "Highway Capacity Manual" (HCM) approaches that would quantify a composite level of service of intersections under mixed flow environment [11-13]. Chen et al. (2007) summarize the impact of trapped bicycles on the through vehicular traffic from four types: a. blockage by bicycles at the beginning of the green phase; b. influence of waiting bicyclists; $c$. influence of traversing bicyclists; and d. influence of trapped bicyclists in the intersection [14]. However, most of these approaches have not paid enough attention to mixed traffic environment, particularly in the Chinese cities.

Generally, intersection capacity analysis provides help in understanding, designing and organizing the passing traffic elements, including bicycle flow. Raksuntorn et al. (2003) recommended that capacity of a bicycle lane at intersections is affected by the saturation flow rate and could be estimated by the number of queues or the width of the bicycle lane [15]. Qian et al. (2010) analyzed the capacity of right-turn motor vehicles that are seriously disturbed by bicycles at twophase signalized intersections in China, and found that bicycle flow volume ranging from 500 to 1,500 bic per hour has a great impact on the capacity of right-turn motor vehicles [16]. In the recent research by Zhang et al. (2009), a new concept of pedestrian group based on gap acceptance theory was proposed to measure how the capacity of right-turn lane vehicle movement at signalized intersections is affected quantitatively by pedestrians and bicycles with regard to different signal phases [17]. Unlike the above Highway Capacity Manual based analysis and approaches, Li et al. (2009) used the theory of fluid mechanics to estimate the capacity of bicycle lanes regarding the interference of other mode traffic elements [18]. However, the process of how to determine the model parameters was still not clear and its effectiveness was beyond verification as well.

The city of Xi'an has always encouraged bicycle commuting among students, faculty staff and visitors, and thus has nationally earned the title of "Bicycle Friendly Community" from the League of China bicyclist [19]. Unfortunately, the problem of how to relate the bicycle traffic to motorized vehicle flow harmoniously, especially within the intersection location, has remained unsolved. Since the conflicting vehicle flows that bicyclists encounter at signalized inter- sections change periodically and a large quantity of them has no respect toward traffic signals, it is difficult to estimate the capacity of bicycle flow through a HCM based model under mixed traffic environment [20]. In this project, therefore, a total of 4 typical signalized intersections in Xi'an with varying motor and bicycle traffic volumes were videotaped for a total of approximately 2 hours (7:30 AM to 8:30 AM and 5:30 PM to 6:30 PM) so as to achieve the traffic flow data from signalized intersections. Thus, this paper discusses the processing procedure, results, case verification and analysis of capacity estimation approach, respectively. It concludes consequently with general remarks and comments about the overall works in the final section.

\section{BICYCLE GATHERING - DISPERSING PROCEDURE}

\subsection{Fluid feature of bicycle flow}

Generally, bicycles pass a signalized intersection following a stream of fluid rather than a single particle behaviour. However, when bicycle density is low and space of bikeways is sufficient for bicycle passing, such fluid dispersion feature is not obviously observed. At higher density conditions, platoon queues and each individual is willing to pass the intersection in case of available space. Thus, dispersion motion of bicycle platoon could be easily recorded.

For easy understanding, let us assume a platoon of bicycles (pulse of fluid) passing through the green of every signal at signalized intersection as a "flow" goes where there is no "resistance", known as bicycle fluid dispersion or diffusion. This phenomenon could be explained by "space occupation theory" [18].

During the red light period, arriving bicycles stop at the parking line and form a queue. As soon as green light comes, the bicycle flow attempts to speed up from the stop line and pass through the intersection, and thus the bicycle density gradually decreases. In actual observation, however, right-turn vehicles, pedestrians and bicycle expansion all have a significant impact on platoon passing efficiency, which in turn cuts down the capacity of overall signalized intersection [21].

\subsection{Fluid dispersion model}

Obviously, bicyclists pass through a signal cycle at three stages:

a. waiting and queuing at a red traffic light,

b. dispersion through intersection in the green light, and

c. conversion into free flow out of intersection. 


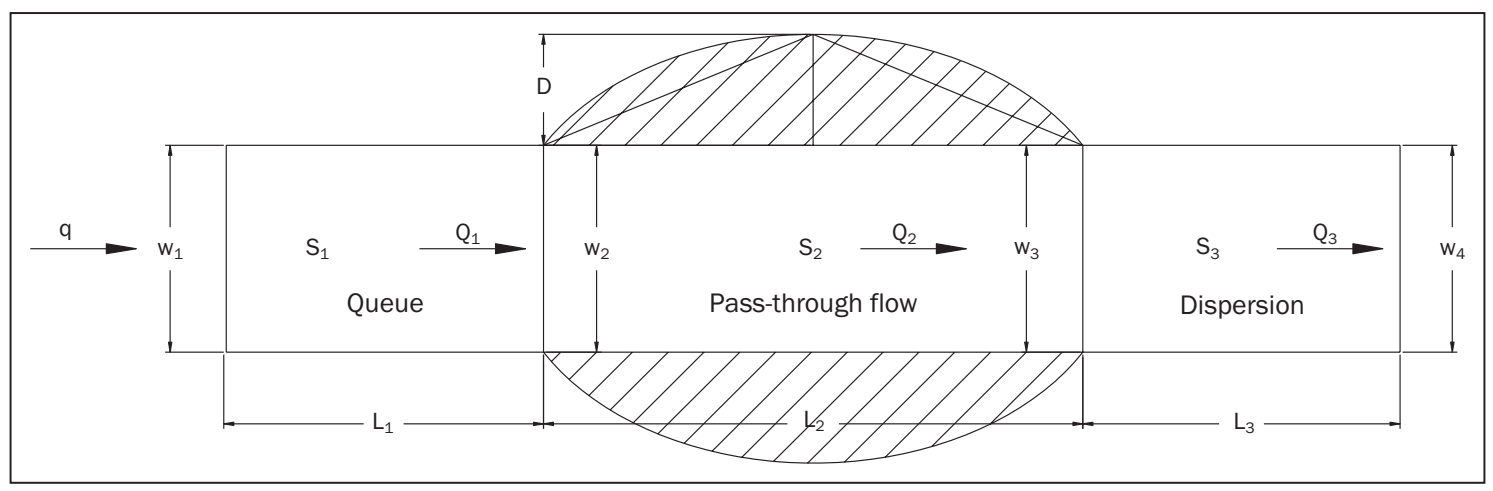

Figure 1 - Queue - dispersion model of bicycle flow at signalized intersection

Since traffic flow is compressible, the activity of bicycles passing through the signalized intersection could be described as fluid in a "pipe line", as shown in Figure 1.

From Figure 1, the following could be seen:

(1) $W_{1}, W_{2}, W_{3}$, and $W_{4}$ are the widths of bicycle lane upstream of intersection, at stop line, at exit line, and downstream of intersection, respectively. For simplification, $W_{i}(i=1,2,3,4)$ could be considered equivalent, as discussed in Section 3. $W_{0}$ denotes the approximate width of one passing bicycle that equals horizontal safety space $0.6 \mathrm{~m}+$ swing space $0.25 \mathrm{~m} \times 2$ in both sides $=1.1 \mathrm{~m}[18,22]$.

(2) $S_{1}$ is the area of bicycle queuing in front of stop line ("inlet pipe"); $S_{2}$ is the area of intersection between the stop line and the exit line ("pipe connection”), where the oblique line (see Figure 1) reflects the space of bicycle expansion and dispersion through occupying motor vehicle and pedestrian lanes in a mode of arc trajectory through the intersection. This process, performing in the bicycle queuing length, is not unrestricted, and only occurs under a certain volume of bicycles within a limited space. $S_{3}$ is the area of bicycle dispersion to free flow at downstream intersection (outlet pipe).

(3) $q$ is for the arrival rate of bicycle group: $q=\Delta N / \Delta t$, or $q=\mathrm{d} N / \mathrm{d} t$, where $N$ is the number of arrival bicycles during the period of $t$. For $S_{i}(i=1,2,3), q_{i}$ $(i=1,2,3)$ is used to denote the arrival rate within each signal cycle, respectively. In fact, bicycle platoon follows the similar process within the intersection location: waiting, queuing, diffusing, and leaving, and thus upstream flow $q$ brings significant effect on the traffic of downstream intersection, following an impulse pattern accordingly rather than a random one. However, $q$ reflects an average arrival state and could be explained by uniform distribution in section $S_{1}$ during a long period.

(4) $N_{q}$ is the number of bicycles gathering in front of red light with duration $C-G_{e}$ that is estimated by $N_{q}=q\left(C-G_{e}\right)$; Furthermore, $S_{1}$ occupied by those bicycles is $q\left(C-G_{e}\right) S_{b}$, where $S_{b}$ is the area occupied by one bicycle. If we take standard defi- nition for density $\rho=\Delta N / \Delta L$, then the number of bicycles occupying the area $S_{1}$ is $N_{q}=\rho_{1} \cdot S_{1} / W_{1}$. So one can state the relation $\rho_{1} \cdot S_{1}=q\left(C-G_{e}\right) W_{1}$.

(5) $Q_{i}(i=1,2,3)$ is the volume of queuing bicycles, that of bicycles passing through and that of dispersing bicycles, respectively.

(6) $L_{1}=S_{1} / W_{1}=q p_{1}^{-1}\left(C-G_{e}\right)$ is the length of bicycle queue in front of stop line; $L_{2}$ is the intersection distance that is the length from the first crosswalk line to the first line encountered on the other side of the intersection. $L_{3}$ is the distance that takes the bicycle flow to disperse from the compressed state into free flow; $D$ is the maximum expanding length of bicycle flow over both sides through the intersection.

\subsection{Influence of bicycle dispersion}

In case of green traffic light, motorway and pedestrian walkway will be occupied by bicycles due to bicycle faster start performance, and thus platoon flow might diffuse around right - left spaces ("virtual widened lanes") [23].

Moreover, $W_{3}$ has no "bottleneck" effect on the bicycle flow within the intersection and at the "outlet pipe", because pedestrians reach the exit line behind bicyclists generally due to their lower crossing velocity than the latter ones. All these enhance the bicycle capacity at signalized intersections effectively. If the extent of bicycle dispersion at one side is $D$, then the virtual width of "outlet pipe" is $\left(W_{3}+2 D\right)$.

\section{FLUID MODEL OF BIKEWAY CAPACITY}

\subsection{Density function of bicycle flow}

During green light phase, the first bicyclist takes time $T$ to arrive at $W_{3}\left(T<G_{e}\right.$, and $G_{e}$ is valid green time that is less than the duration of general green time). Over the time of $0 \sim T$, the bicycle flow, in a dynamic diffusing state, is compressed from $S_{1}$ to $S_{2}$, 
and $\rho_{i}(i=1,2)$ are density values in $S_{1}$ and $S_{2}$, respectively.

If the bicycle flow obtains the dynamic balances in $S_{i}(i=1,2)$, then it yields:

$\rho_{1} S_{1}+W_{1} q T=\rho_{2} S_{2}$.

Thus, the density in pipe connection $S_{2}$ could be transferred from Eq. (1) into $\rho_{2}=\left(\rho_{1} S_{1}+W_{1} q T\right) / S_{2}$. During the time interval from $T$ to $G_{e}$, bicycles leave $W_{3}$, and the following ones fill up from $W_{2}$ with the arrival rate $q$. Finally, the changed number of bicycles in $S_{2}$ could be measured through a differential model:

$W_{2} q \mathrm{~d} t-V\left(W_{3}+2 D\right) \rho_{2} \mathrm{~d} t=\mathrm{S}_{2} \mathrm{~d} \rho_{2}$

where $V$ is the spot speed of bicycle flow at the exit line.

Reconsidering Eq. (2), a non-homogeneous linear differential equation of the first order is obtained:

$\frac{\mathrm{d} \rho_{2}}{\mathrm{~d} t}+\frac{V\left(W_{3}+2 D\right)}{S_{2}} \rho_{2}=\frac{W_{2} q}{S_{2}}$

and its solution could be expressed in:

$\rho_{2}(t)=\frac{W_{2} q}{V\left(W_{3}+2 D\right)}+C_{0} \cdot \exp \left[-\frac{V\left(W_{3}+2 D\right)}{S_{2}} t\right]$

subject to

$$
\rho_{2}(0)=\rho_{2}=\left(\rho_{1} S_{1}+W_{1} q T\right) / S_{2}, \text { for } t=0,
$$

where $C_{0}$ is an integral constant.

Thus, $C_{0}$ could be derived from Eq. (4) as:

$C_{0}=\frac{\rho_{1} S_{1}+W_{1} q T}{S_{2}}-\frac{W_{2} q}{V\left(W_{3}+2 D\right)}$.

Therefore, Eq. (4) could be rearranged into a determined expression:

$$
\begin{aligned}
\rho_{2}(t)= & \frac{W_{2} q}{V\left(W_{3}+2 D\right)}+\left[\frac{\rho_{1} S_{1}+W_{1} q T}{S_{2}}-\frac{W_{2} q}{V\left(W_{3}+2 D\right)}\right] \\
& \cdot \exp \left[-\frac{V\left(W_{3}+2 D\right)}{S_{2}} t\right] .
\end{aligned}
$$

\subsection{Capacity estimation model}

The flow rate of passing bicycles that were released from the exit line and passed through section $W_{3}$ at moment $t$ from $T$ to $G_{e}$ could be approximated as:

$$
\begin{aligned}
q(t)=\frac{\mathrm{d} N(t)}{\mathrm{d} t}=\rho_{2}(t) \frac{W_{3}+2 D}{W_{0}} V=\frac{W_{2}}{W_{0}} q+ \\
+\left[\frac{V\left(\rho_{1} S_{1}+W_{1} q T\right)\left(W_{3}+2 D\right)}{W_{0} S_{2}}-\frac{W_{2}}{W_{0}} q\right] . \\
\cdot \exp \left[-\frac{V\left(W_{3}+2 D\right)}{S_{2}} t\right]
\end{aligned}
$$

Differential

$$
\mathrm{d} N(t)=\rho_{2}(t) \frac{W_{3}+2 D}{W_{0}} V \mathrm{~d} t
$$

represents the number of bicycles passing through the signalized intersection during time $\mathrm{d} t$. For the period of $T \sim G_{e}$, the number of bicycles $N_{c}$ that have passed through exit line satisfies:

$N_{c}=\int_{T}^{G_{e}} N(t) \mathrm{d} t$.
Combining Eq. (7) and Eq. (8), it reaches:

$$
\begin{gathered}
N_{c}=\frac{W_{2} q\left(G_{e}-T\right)}{W_{0}}+\left[\frac{W_{2} S_{2} q}{V W_{0}\left(W_{3}+2 D\right)}-\frac{\rho_{1} S_{1}+W_{1} q T}{W_{0}}\right] . \\
.\left[\exp \left(-\frac{V\left(W_{3}+2 U\right)}{S_{2}} G_{e}\right)-\exp \left(-\frac{V\left(W_{3}+2 D\right)}{S_{2}} T\right)\right]
\end{gathered}
$$

In one cycle it is obvious that the number of passing bicycles is proportional to the valid green time $G_{e}$ and a shorter $T$ also brings a heavier bicycle flow $N$. The capacity of bikeway $N_{\text {cap }}$ could be estimated as the number of bicycles passing through in one hour by relation:

$N_{\text {cap }}=3,600 N_{c} / C$,

where $C$ is the pre-timed length of signal cycle (measured in $s$ ) and $N_{c}$ is the total passing bicycles per signal cycle estimated by Eq. (8).

Eq. (10) is used to estimate how many bicycles could pass through the intersection entrance (bikeway) in one hour, and the capacity of signalized intersection equals the sum of $N_{\text {cap }}$ values of total bikeways. Of course, this capacity estimation model does not take into account some conflict factors (right-turning vehicle, pedestrians, etc).

\subsection{Dispersion model calibration}

From Figure 2 it follows that $S_{1}=W_{1} L_{1}$, and $S_{2}=W_{2} L_{2}+2 S_{A}$, where $S_{A}$ is the shaded area. By Figure 2,

$$
S_{A}=\theta R^{2} / 2-(R-D) L_{2} / 2 \text {, }
$$

where $R=0.5 L_{2} \operatorname{ctg} 0.5 \theta+D$. For a small $\theta$, $\operatorname{ctg} 0.5 \theta=\cos 0.5 \theta / \sin 0.5 \theta=2 / \theta$, and thus it yields $R=L_{2} / \theta+D$, and $S_{A}=D L_{2}+\theta D^{2} / 2 \approx D L_{2}$. For the total dispersion area, we obtain

$$
S_{2}=\left(W_{2}+2 D\right) L_{2} \text {. }
$$

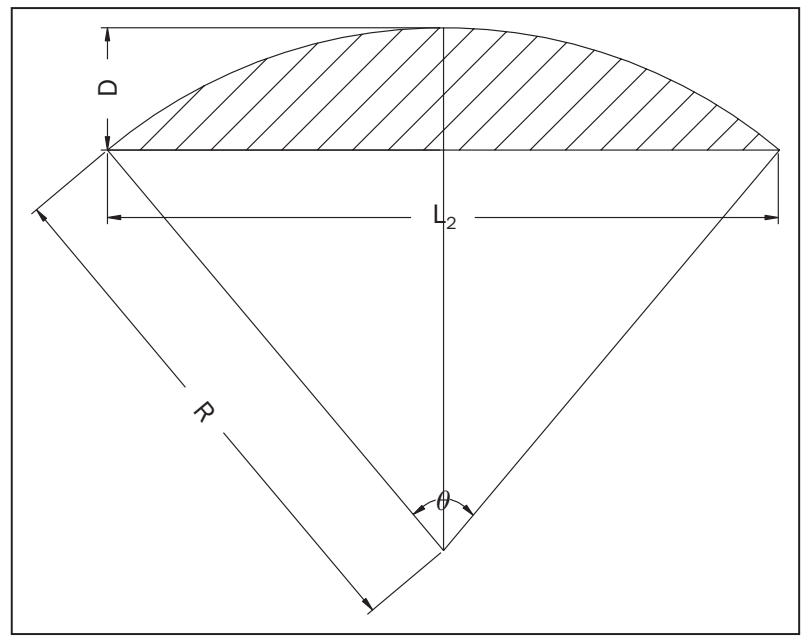

Figure 2 - Parameter determination for $W_{2}$

For a general signalized intersection, it could be considered that $W_{1}=W_{2}=W_{3}=W_{4}=W$ (as shown in Figure 3 ), and bicycles cross the intersection distance 
$L_{2}$ at a constant speed $V\left(L_{2}=V T\right)$. The number of passing bicycles per unit width, within a cycle, could be estimated in $N_{\text {cap }}^{\prime}=N_{c} W_{0} / W$. Eq. (9) is then transferred into:

$N_{\text {cap }}^{\prime}=q\left[G_{e}-T+\frac{C-G_{e}}{W}\left(e^{-1}-e^{-\frac{G_{e}}{T}}\right)\right]$.

Due to Eq. (10), the bicycle capacity per unit width at the signalized intersection in one hour could be estimated by Eq. (11), and it yields overall capacity $N^{\prime \prime}$ cap for any bikeway width through $(3,600 / C) \cdot\left(W / W_{0}\right) \cdot N_{\text {cap }}^{\prime}$ as:

$$
N^{\prime \prime}{ }_{\text {cap }}=3,600 q\left[\frac{G_{e}-T}{C} \cdot \frac{W}{W_{0}}+\frac{1}{W_{0}}\left(1-\frac{G_{e}}{C}\right)\left(e^{-1}-e^{-\frac{G_{e}}{T}}\right)\right] \text {. }
$$

\section{CASE STUDY}

\subsection{Data collection process}

In selecting the intersections, the following selection criteria were used:

a. sufficient bicycle volume;

b. a variety of crosswalk distances;

c. signalized intersection;

d. few pedestrian - vehicle conflicts;

e. perfect sight distance for right turning vehicles and pedestrians;

f. effective traffic signs and markers;

g. an acceptable vantage point for the video recorder (around higher buildings, etc.).

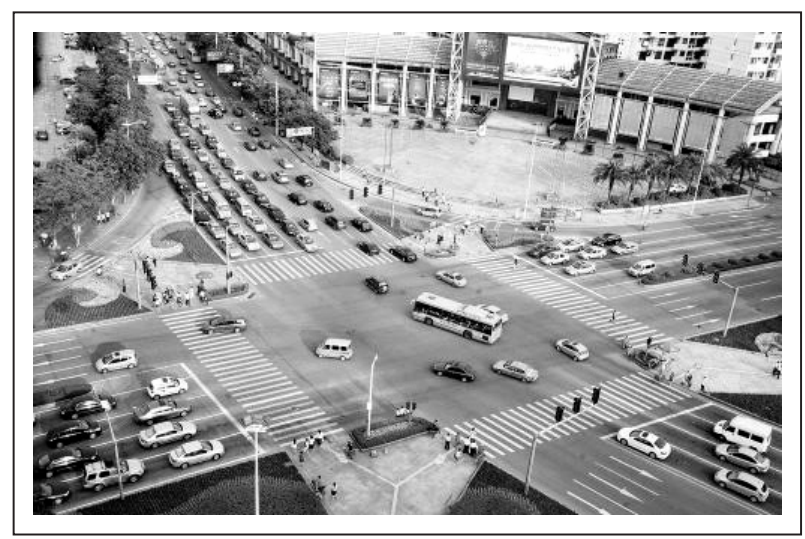

Figure 3 - A general signalized intersection in China. This photo shows a heavy traffic signalized intersection at Shibo Square in Dongguan, China, cited from http://dg.house.sina.com.cn/2010-07-07/071436386.html, and here the $W_{i}$ refers to the width of pedestrian lane that has equivalent breadth for each direction.

Four 4-way intersections were identified to be videotaped and ultimately recorded approximately for two hours at each of the four signalized intersections near the Chang'an University Campus and Xiaozhai commercial centre. Figure 4 shows the overhead view of the four signalized intersections, among which three link two arterials; and the remaining one $\left(4^{\text {th }}\right.$ intersection of East Xiaozhai Rd. - Cuihua Rd.) connects the arterial West Xiaozhai Rd. and the sub-arterial Cuihua $\mathrm{Rd}$.

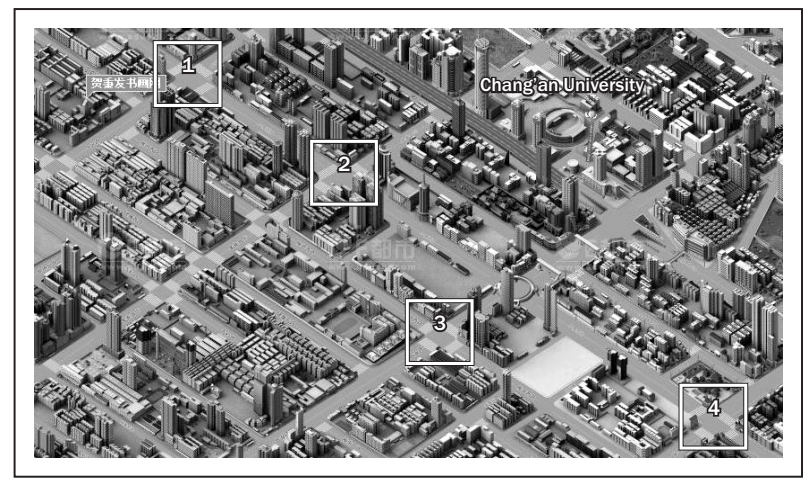

Figure 4 - Overhead view of surveyed signalized intersections. Signalized intersection: 1. intersection of West Xiaozhai Rd. - Hanguang Rd.; 2. intersection of West Xiaozhai Rd. - Zhuque Str. Inter.; 3. intersection of West Yanta Rd. - Chang'an Rd.; 4. intersection of East Xiaozhai Rd. - Cuihua Rd.

The observations were made during the morning (7:30 - 8:30 a.m.) and afternoon (5:30 6:30 p.m.) peak periods on September 23, 2010 using digital video cameras with wide-angle lenses to capture the bicycle message. The weather was mild for all observations and the traffic flow was in perfect order at each intersection. For the survey of percentage velocity of bicycles, the number of samples to be observed is estimated by:

$n \geq\left(\frac{\sigma K}{E}\right)^{2}\left(1+\frac{r^{2}}{2}\right)$

where $n$ is the number of observed samples; $\sigma$ is the standard deviation of observations in this research that ranges from $5 \mathrm{~km} / \mathrm{h}$ to $10 \mathrm{~km} / \mathrm{h}$ [24]; $K$ is a constant at a given level of confidence; $E$ is the maximum allowed error for velocity $[\mathrm{km} / \mathrm{h}] ; r$ is the adjustment factor of the calculation.

In this observation it was noticed that the passing velocity of the bicycle through the intersection varies between $8 \mathrm{~km} / \mathrm{h}$ and $12 \mathrm{~km} / \mathrm{h}$ and thus $\sigma=5 \mathrm{~km} / \mathrm{h}, E$ $=0.5 \mathrm{~km} / \mathrm{h}$, and $K=1.96$ for a $95 \%$ confidence level were chosen [23]. Because the average velocity $V$ is used to estimate the travelling time of bicycle passing from stop line at inlet pipe to exit line at outlet pipe, thus we consider $r=0.00$ and we obtain that the minimum sample is 384 observations. The majority of the observed bicyclists are young adults because of the proximity of the intersections to the Chang'an University Campus, College of Jiaoda Medicine Campus and Xiaozhai commercial centre.

Table 1 summarizes for each intersection the distance of observed intersections, width of pedestrian lanes and signal parameters of intersections. 
Y. Wang, G. Wei, X. Zhu, Y. Pei: Capacity of Bicycle Platoon Flow at Two-Phase Signalized Intersection: a Case Analysis of Xi'an City

Table 1 - Explanatory variables of observed signalized intersections

\begin{tabular}{|c|c|c|c|c|}
\hline Intersection & 1 & 2 & 3 & 4 \\
\hline Distance $L_{2} / m$ & 52 & 45 & 53 & 38 \\
\hline Signal cycle $\mathrm{C} / \mathrm{s}$ & 115 & 120 & 140 & 100 \\
\hline Green time $\mathrm{G}_{\mathrm{e}} / \mathrm{s}$ & 35 & 45 & 50 & 36 \\
\hline Number of samples $n$ & 422 & 336 & 418 & 373 \\
\hline Observation spot & Hanguang Rd. & West Xiaozhai Rd. & Zhuque Str. & West Xiaozhai Rd. \\
\hline Flow direction & East $\rightarrow$ West & North $\rightarrow$ South & West $\rightarrow$ East & South $\rightarrow$ North \\
\hline
\end{tabular}

For experiment simplicity, number of bicycles in one direction of inlet pipe at each signalized intersection is recorded. At West Xiaozhai Rd. - Hanguang Inter., for example, the spot is chosen at the Northeast corner (see Figure 4), and the observation only includes bicycles that cross the Hanguang $R d$. through pedestrian line from east to west at the north inlet pipe of this intersection.

\subsection{Parameter extraction of bicycle platoon}

To extract the speed distribution features of bicycle flow from the videotapes, a team of undergraduate students manually reviewed the videotapes. Because of the constraints of time and resource, a computeraided video reconstruction procedure had to be used, that tracks the vehicle movements and transforms the positions of bicyclists through an intersection, which manually started and stopped the videotape for each bicyclist to report the time that the bicyclist entered the intersection (crossed the first crosswalk line) and exited the intersection (crossed into the crosswalk on the far side of the intersection).

Reasonably, there are numerous difficulties in recording the bicycle passing message, for example, occlusion in observing the stop and start points and short display of times on the videotape only to the full second with 30 frames per second. Therefore, enough exercise should be undertaken to test and improve the reliability of extracting the bicycle passing movements from the videotapes.

In addition, special observations recorded from the videotapes including interactions between bicyclists, pedestrians and automobiles were also noted, and most illegal bicycle movements, such as diagonal travel across the intersection, were excluded from the original observations. Finally, the average crossing velocity of bicyclists could be estimated through $V=L_{2} / T$, based on the valid observations (see Table 1). Table 2 summarizes the distribution features of crossing velocities of bicyclists.

With respect to the videotape observation results, the minimum safety headway per unit width is $1.75 \mathrm{~s}$ and thus the maximum arrival rate $q_{\max }=1 / 1.75=0.57 \mathrm{bic} / \mathrm{s}$, and the maximum density of bicycle flow reaches $0.65 \mathrm{bic} / \mathrm{m}^{2}$ at Intersection 2 and the average satisfies $\sum n_{i} \rho_{i} / \sum n_{i}=0.57 \mathrm{bic} / \mathrm{m}^{2}$, where $i=1,2,3,4, n_{i}$ is the $i$-th intersection and $\rho_{i}$ is the observed density of queuing bicycles at Intersection $i$. Here Intersection 1 refers to the Intersection of West Xiaozhai Rd. - Hanguang Rd, as shown in Figure 4. In addition, the average velocity of bicycle passing through is $\sum n_{i} V_{i} / \sum n_{i}=10.82 \mathrm{~km} / \mathrm{h}(3.01 \mathrm{~m} / \mathrm{s})$, derived from the travelling speed $V_{i}$ at Intersection $i$. Consequently, it comes up to $11 \mathrm{~km} / \mathrm{h}$ if the impact of bicycle violators and right-turn vehicle is neglected.

\subsection{Capacity determination and comments}

Let us make a deep analysis into Eq. (12) choosing $q=0.57 \mathrm{bic} /(\mathrm{s} \cdot \mathrm{m}), \quad V=3.01 \mathrm{~m} / \mathrm{s}, \quad T=L_{2} / V$, and then the relation of $L_{2}, C$, and $G_{e}$ could be quantitatively expressed. If we use $C=130$ s and an intersection length vector $L_{2}=[35,40,45,50,55,60]$ , for example, we compare the cases: $G_{e-1}=40$ s and $G_{e-2}=50$ s, the green time of signal of Intersection 1 and Intersection 2. Following Eq. (12), we conclude

$$
N_{\text {cap -1 }}^{\prime \prime}=[1452,1370,1285,1198,1110,1021] \text { and }
$$

Table 2 - Derived parameters for capacity modelling

\begin{tabular}{||l|c|c|c|c|c||}
\hline \multicolumn{1}{|c|}{ Variables } & Unit & Inter. 1 & Inter. 2 & Inter. 3 & Inter. 4 \\
\hline \hline$W$ & $\mathrm{~m}$ & 2.5 & 3.2 & 3.4 & 2.2 \\
\hline$V$ & $\mathrm{~s}$ & 17.54 & 14.29 & 18.12 & 12.63 \\
\hline$\rho / W$ & $\mathrm{~km} / \mathrm{h}$ & 10.67 & 11.34 & 10.53 & 10.83 \\
\hline$q / W$ & $\mathrm{bic} / \mathrm{m}^{3}$ & 0.52 & 0.65 & 0.55 & 0.57 \\
\hline$N^{\prime}{ }_{\text {cap }} / W$ & $\mathrm{bic} /(\mathrm{s} \cdot \mathrm{m})$ & 0.27 & 0.49 & 0.52 & 0.43 \\
\hline$N^{\prime \prime}{ }_{\text {cap }} / W$ & $\mathrm{bic} /(\mathrm{s} \cdot \mathrm{m})$ & 6.71 & 18.78 & 20.76 & 13.92 \\
\hline \hline
\end{tabular}

Inter. $i=$ Intersection $i(i=1,2, \ldots, 4)$. 


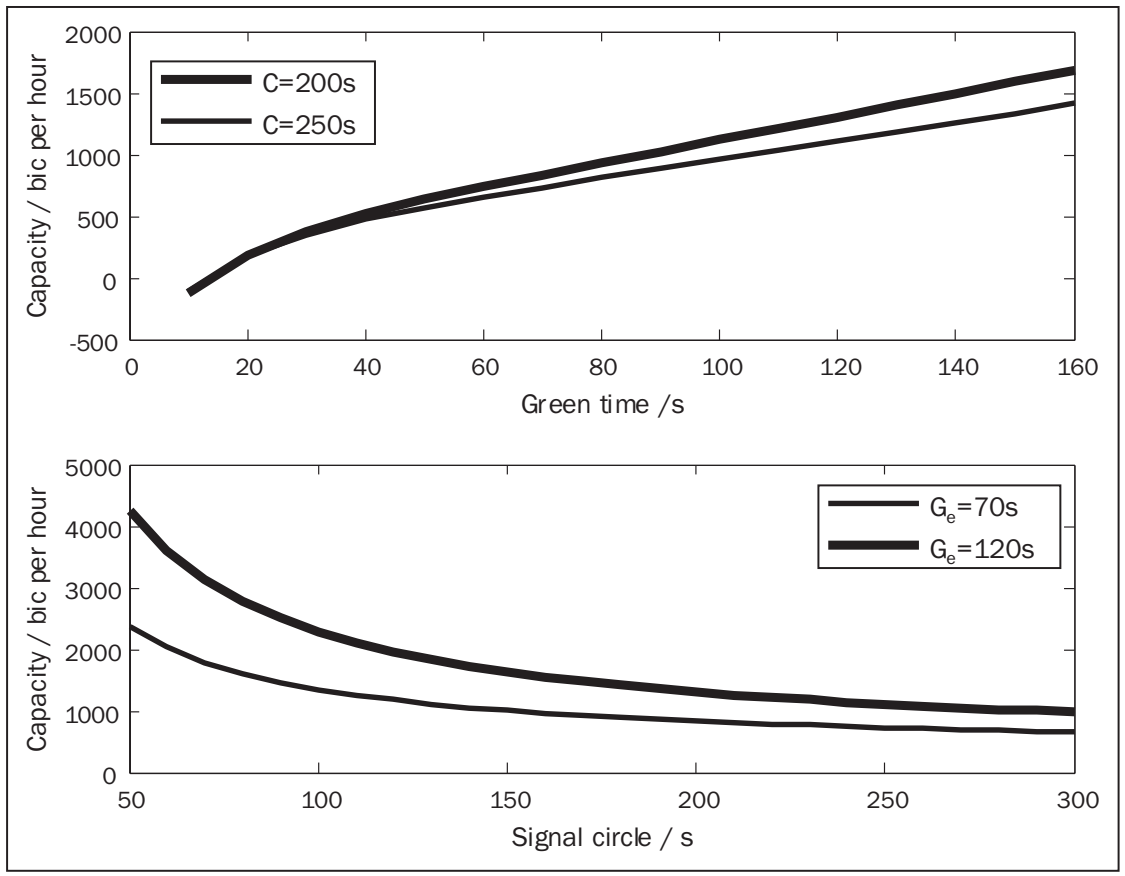

Figure 5 - Effects of green time $G_{e}$ and signal cycle $C$ on capacity for Intersection 1

$N_{\text {cap-2 }}^{\prime \prime}=[2169,2081,1991,1899,1805,1710]$.

Obviously, the capacity per unit width decreases with intersection distance linearly. In another case, the capacity vector reaches

$$
N_{\text {cap }}^{\prime \prime}=[1401,1638,1864,2081,2294,2503] \text {, }
$$

if we consider $C=130 \mathrm{~s}, \quad L_{2}=40 \mathrm{~m}$, and $G_{e}=[35,40,45,50,55,60]$ in second. Here if $W=2.5 \mathrm{~m}$ and $T=13.289 \mathrm{~s}$ due to intersection distance $L_{2}=13.289 \times 3.01=40 \mathrm{~m}$, we have made a numerical test to check the effect of signal parameters on capacity value, as shown in Figure 5.

The bicycles that arrived during red time have to queue behind the wait line and as soon as the green time comes, they pour into the intersection in a compressed state that the arriving bicycles are at this moment. During the period of $T$, generally, the density of bicycles within the intersection decreases till the leaving flow rate at outlet pipe is equal to the arrival flow rate at inlet pipe. According to Eq. (6), we have a density asymptote $\rho_{2}=W q / V(W+2 D)$ for bicycle flow within the intersection. Moreover, we obtain the capacity asymptotes

$$
\lim _{T \rightarrow G_{e}^{-}} N_{\text {cap }}^{\prime \prime}=0 \text { and } \lim _{T \rightarrow C^{-}} N_{\text {cap }}^{\prime \prime}=3600 q\left(1-\frac{T}{C}\right) \frac{W}{W_{0}}
$$

through Eq. (12), respectively.

In general, the relation is drawn between the capacity of bikeway and signal parameters by Eq. (12), as shown in Figure 6. Obviously, the growth rate of capacity declines disproportionately along with the increasing signal cycle length or green time length. The methods of increasing bikeway capacity, such as adding green time or extending signal cycle, etc., are not always effective. In most signalized intersections, therefore, green time and signal cycle length generally remain 40 70s and 110 180s, respectively.

Through reconsidering the distracted messages from observations, the theoretical capacities of four signalized intersections are measured by Eq. (11) and Eq. (12) and Table 2 also shows the calculation results. On the other hand, we identify the number of bicycles within the maximum flow rate and the correspondent signal cycle. Then the observed capacities could be determined by Eq. (10), as listed in Table 3.

Compared with theoretical capacities that were measured by the proposed model in this research, obviously, the observed values are a bit lower, which contributes to the neglect of influence induced by left turn vehicles, pedestrian crosswalk and weather and other factors. Moreover, the difference of bicycle velocity between the older and the younger also helps reduce the capacity value. Of course, we reach a more satisfactory result than those by HCM 2000 and JJ37-90, for the latter two do not pay enough attention to the fixed traffic environment at signalized intersections. Of course, some facilities at signalized intersections providing crossing convenience for bicyclists also help improve the capacity and in recent years, this has already had a wide awareness in China, and Wuhan has set a good example (Figure 7) for all involved.

\section{CONCLUSION}

Bicycle travel holds an important position in the daily commutes, regardless of the weather. Therefore, how to update the preferred facilities capacity and per- 


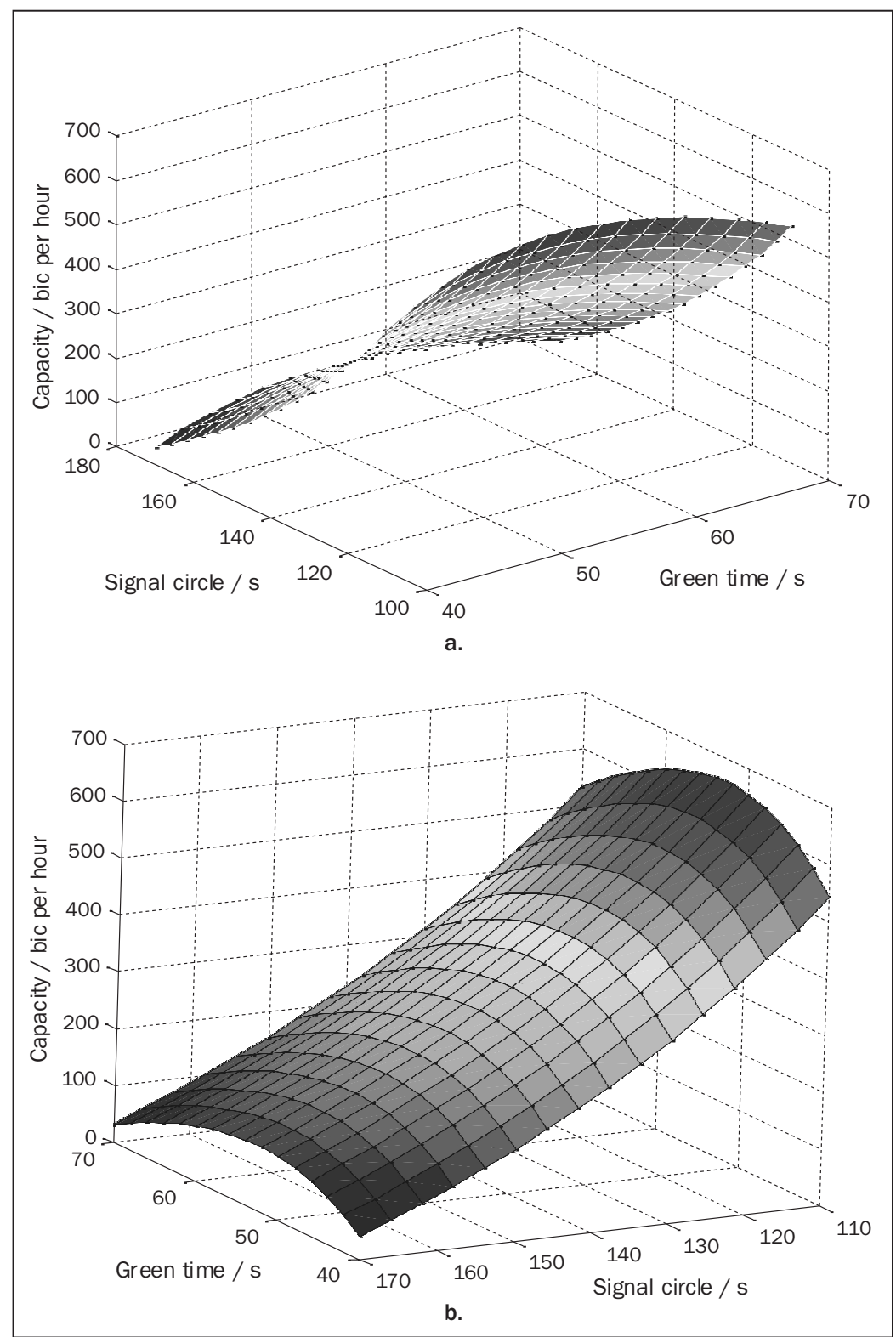

Fiøure 6 - Cvlindrical relation of bikewav capacitv and signal parameters for Intersection 1

Table 3 - Comparison of bikeway capacity estimation results

\begin{tabular}{|l|c|c|c|c|c||}
\hline \multicolumn{1}{|c|}{ Intersection } & Unit & 1 & 2 & 3 & 4 \\
\hline \hline Maximum bicycles flow & bic & 31 & 154 & 167 & 57 \\
\hline The i-th cycle of signal & - & 17 & 19 & 13 & 23 \\
\hline Observed capacity & bic/h & 970 & 4,620 & 4,294 & 2,052 \\
\hline Capacity in proposed model & bic/h & 1,195 & 5,245 & 5,613 & 2,206 \\
\hline Capacity in HCM 2000 & bic/h & 1,384 & 2,181 & 2,206 & 1,440 \\
\hline Capacity in JJ37-90 & bic/h & 1,029 & 3,129 & 2,701 & 1,682 \\
\hline Empirical Capacity in JJ37-90 & bic/h & 4,091 & 5,236 & 5,564 & 3,600 \\
\hline
\end{tabular}

Flow rate is measured in the number of passing bicycles per signal cycle and maximum rate refers to the flow rate under saturated condition; Observed capacity $=3600 \times$ maximum rate of bicycle flow $\div$ length of signal cycle;

Capacity in $\mathrm{HCM} 2000=2000\left(\mathrm{G}_{e} / C\right)\left(W / W_{0}\right)$;

Capacity in $J J 37-90=3600 N_{b t} W_{0} /\left[t_{f}(W-0.5)\right]\left(W / W_{0}\right)$, where $t_{f}$ is the length of observation time equalling $G_{e} ; N_{b t}$ is the number of passing bicycles within t;

Empirical capacity $=$ Possible capacity of bicycle flow in $\left(2100\right.$ or 1800) $\times\left(W / W_{0}\right)$ for case with and without barriers, respectively; HCM 2000 is referenced as: Transportation Research Board. Highway Capacity Manual 2000 edition, 2000;

CJ 37-90 is referenced as: Beijing General Municipal Engineering Design \& Research Institute. Urban Road Design Standards, 1991. 


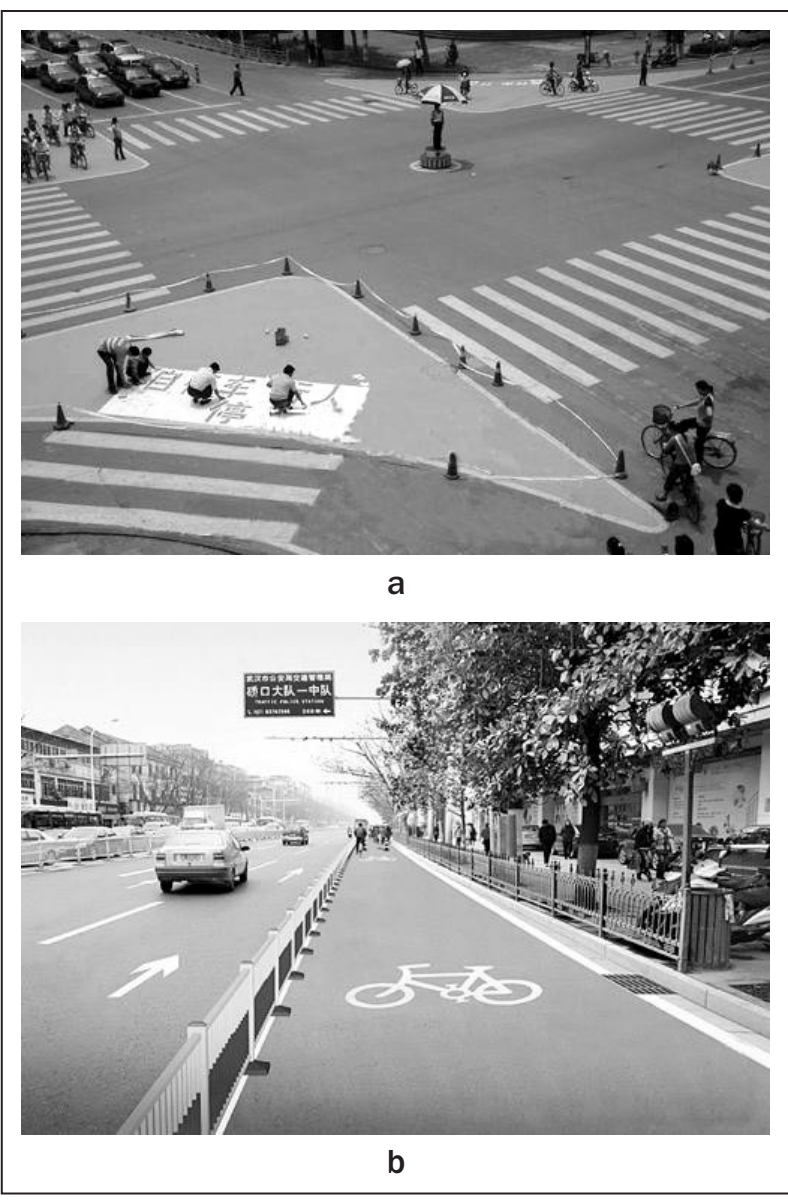

Figure 7 - Bicycle traffic improvement measures at Wuhan, China. a. temporary island of bicycle parking at signalized intersection; b. bicycle lane

sonal sense of level of service is particularly necessary and important (but not sufficient) to create a humanoriented traffic environment.

Intersections are the crossing nodes of traffic streams, including hurrying bicyclists as well as a high pedestrian-vehicle flow. Thus, it is worthwhile pointing out that the key problem in maintaining a perfect traffic order for overall networks depends on the performance of bottlenecks (e.g., closely-spaced intersection, transport hub, etc.) for urgent needs.

On the basis of conventional fluid dispersion theo$r y$, this research proposes a capacity estimation model of bicycle flow at signalized intersections, and discusses such parameters as signal cycle, green time, and bicycle arrival rate, etc., that influence the bicycle capacity performance. According to actual observations from four signalized intersections around Chang'an University campus in Xi'an, a case example is performed to check the effectiveness of this proposed model of capacity estimation, compared with those derived through HCM 2000 and II37-90. Of course, these works turn to have certain help in theory and instruction for improving signal timing and intersection channelization for bicyclists.
However, mixed traffic is the main characteristic of most cities in China. How to understand the capacity characteristics of bicycle flow, to determine the cooperative control of traffic elements, and to achieve the balance of development of non-motor vehicles and motor vehicles have been for quite a long time issues that need to be resolved. It is also found in the observations that part of the effective time is wasted in waiting for the right-turn vehicles and disordered traffic decreases the capacity, even causing the expected jams. Moreover, the intersection types, weather conditions, pavement conditions, behaviours of bicyclists, pedestrian crosswalk and vehicle driving are not considered in this research and all these issues will be considered in the future works.

The authors believe that it is an important topic that has not been dealt with sufficient attention in the past and that further research will become heated to help in formulating a system design of traffic management and guidance around intersection locations in the overall urban areas, and human-oriented technique (combining behaviour feature, environment theory and GIS) helps create more liveable places for all the involved.

\section{ACKNOWLEDGEMENT}

This project is supported by the Special Fund for the Basic Scientific Research of Central Colleges, Chang'an University (No. CHD2010JC019). Here we also wish to thank editors, anonymous reviewers and authors of cited papers, for their detailed suggestions, precise comments and continuous help, whose dedication contributed to this research work, which would not have been feasible without their support.

\section{王永岗}

E-mail: sdqdwyg@163.com

长安大学公路学院, 西安 710064 , 中国

韦刚

中交第一公路勘察设计研究院有限公司, 西安 710075 ,

中国

朱旭

长安大学公路学院, 西安 710064 , 中国

裴玉龙

哈尔滨工业大学交通科学与工程学院, 哈尔滨 150090 , 中国

\section{摘要}

\section{两相位信号交叉口自行车流通 行能力: 以西安市为例}

鉴于目前对信号交叉口处自行车通行能力研究不足的 实际情况, 本文基于流体扩散理论提出了一种单位宽度的 自行车流通行能力分析方法, 进而可推广到整个信号交叉 口进口道的计算, 同时可量化分析信号参数 (信号周期、 绿灯时间) 、交通流参数 ( 到达率、密度、穿越速度) 及 交叉口尺寸等指标变化对通行能力的影响。依据西安市小 
寨商业区周边四个典型信号交叉口的自行车流视频采集数 据, 分析结果表明上述指标变化对通行能力值的影响呈线 性全系, 而通过本文所提出方法所计算得到的通行能力值 较HCM 2000标准更为接近于观测值。据此可推断以往研 究中对右转车流和行人交通对自行车通行能力影响的估计 偏低, 但若采用JJ37-90计算自行车道的通行能力则结果 显然偏大，究其原因在于其忽略了对中国城市中混合交通 这一基本前提的考虑。

\section{爸键词}

自行车道通行能力, 信号交叉口, 流体扩散, HCM方 法, 信号参数, 混合交通

\section{LITERATURE}

[1] Chen K. M., Luo X. Q., Ji H., et al.: “Towards the Pedestrian Delay Estimation at Intersections under Vehicular Platoon Caused Conflicts", Scientific Research and Essays, Vol. 5, No. 9, 2010, pp. 941-947

[2] Wang S. L., Liu Z. L., Guo J. F., et al.: "Research on Bicycle Safety at Intersection in Beijing", Proceedings of the 2008 International Conference of Chinese Logistics and Transportation Professionals, Chengdu, China, pp. 4739-4744

[3] Xiong H., Qiu J. D.: "Study on Bicycle Crossing Capacity at Signalized Intersection", Transaction of Beijing Institute of Technology, Vol. 28, No. 2, 2008, pp. 125-128

[4] Qian H. B., Zhang H. L.: "Bicycle Traffic Organization and Treatment at Signalized Intersection", Proceedings of 2009 International Conference on Intelligent Computing Technology and Automation, Changsha, China, pp. 515-518

[5] Dabbour E., Easa S. M.: "Evaluation of Safety and Operational Impacts of Bicycle Bypass Lanes at Modern Roundabouts", Canadian Journal of Civil Engineering, Vol. 35, No. 10, 2008, 1025-1032

[6] Haque M. M., Chin H. C., Huang H. L.: "Modeling Fault among Motorcyclists Involved in Crashes", Accident Analysis and Prevention, Vol. 41, No. 2, 2009, pp. 327335

[7] Zhao H., Wei Z. L., Li W.: "Bicycle-based Courier and Delivery Services in Beijing: Market Analysis", Transportation Research Record, No. 1954, 2006, pp. 45-51

[8] Petritsch T. A., Landis B. W., Huang H. F., et al.: "Bicycle Level of Service for Arterials", Transportation Research Record, No. 2031, 2007, pp. 34-42

[9] Wang D. H., Feng T. J., Liang C.Y.: "Research on Bicycle Conversion Factors", Transportation Research Part A: Policy and Practice, Vol. 42, No. 8, 2008, pp. 11291139

[10] Allen D. P., Hummer J. E., Rouphail N. M., et al.: "Effect of Bicycles on Capacity of Signalized Intersections", Transportation Research Board, No. 1646, 1998, pp. 87-95

[11] Taylor D., Davis W. J.: "Review of Basic Research in Bicycle Traffic Science, Traffic Operations, and Facility
Design", Transportation Research Record, No. 1674, 1999, pp. 102-110

[12] Landis B. W., Vattikuti V. R., Ottenberg R. M., et al.: "Intersection Level of Service for the Bicycle Through Movement", Transportation Research Record, No. 1828, 2003, pp. 101-106

[13] Li J., Yue Z. Q., Wong S. C.: "Performance Evaluation of Signalized Urban Intersections under Mixed Traffic Conditions by Gray System Theory", Journal of Transportation Engineering, Vol. 130, No. 1, 2004, pp. 113121

[14] Chen X. M., Shao C. F., Yue H.: "Influence of Bicycle Traffic on Capacity of Typical Signalized Intersection", Tsinghua Science and Technology, Vol. 12, No. 2, 2007, pp. 198-203

[15] Raksuntorn W., Sarosh I.: "Saturation Flow Rate, Startup Lost Time, and Capacity for Bicycles at Signalized Intersections", Transportation Research Record, No. 1852, 2003, pp. 105-113

[16] Qian D. L., Niu Z. Q.: "Analysis of Capacity and Its Sensitivity of Right-turn Motor Vehicles at Signalized Intersection under Mixed Traffic", China Journal of Highway and Transport, Vol. 23, No. 2, pp. 77-83

[17] Zhang W. C., Yang X. K., Xu Z.: "Study on the Capacity of Right-turn Movement under Pedestrians' Influence at Signalized Intersections", Proceedings of 2009 International Conference of Chinese Transportation Professionals, Harbin, China, pp. 2976-2982

[18] Li L. L., Zhang Y. P., Lan X., et al.: "Research on the Bicycle Capacity at Signalized Intersection Based on Fluid Diffusion Characteristics", Proceedings of 2009 International Conference of Chinese Transportation Professionals, Harbin, China, pp. 1306-1311

[19] Wang D. H., Feng T. J., Liang C. Y.: "Research on Bicycle Conversion Factors", Transportation Research Part A: Policy and Practice, Vol. 42, No. 8, 2008, pp. 11291139

[20] Zegeer J. D., Blogg M., Nguyen K., et al.: “Default Values for Highway Capacity and Level-of-service Analyses", Transportation Research Record, No. 2071, 2008, pp. 35-43

[21] Cheng D. X., Tian Z. Z., Liu H. C.: "Implementing Actuated Signal-controlled Intersection Capacity Analysis with Pedestrians", Transportation Research Record, No. 2071, 2008, pp. 125-130

[22] Molino J. A., Kennedy J. F., Johnson P. L., et al: "Pedestrian and Bicyclist Exposure to Risk: Methodology for Estimation in an Urban Environment", Transportation Research Record, No. 2140, 2009, pp. 145-156

[23] Wei H., Ren F. T., Liu X. M.: "Research on the Relationship between Bicycle Traveling State and Bicycle Road Capacity", China Journal of Highway and Transport, Vol. 6, No. 4, 1993, pp. 3-8

[24] Zhang Y. P., Zhang Y. L., Lan X., et al.: "A Bicycle Flow Diffusion Model at Signalized Intersections", Urban Transport of China, Vol. 6, No. 6, 2008, pp. 41-45, 53 